\title{
Desempenho do pimentão em cultivo orgânico, submetido ao desbaste e consórcio
}

\author{
Marcius Nei Zanin Cesar ${ }^{1}$; Raul de Lucena Duarte Ribeiro²; Patrícia Diniz de Paula²; José Carlos \\ Polidoro $^{2}$; Thomaz da Costa Manera ${ }^{2}$; José Guilherme Marinho Guerra ${ }^{3}$ \\ ${ }^{1}$ IDATERRA,Rodovia MS 080, km 10; 79114-000 Campo Grande-MS; ${ }^{2}$ UFRRJ, BR 465, km 07, 23890-000 Seropédica-RJ; ${ }^{3}$ Embrapa \\ Agrobiologia, C. Postal 74505, 23851-970 Seropédica-RJ; mnzcesar@yahoo.com.br
}

\section{RESUMO}

As cultivares de pimentão Magali R e Magda Super foram comparadas no sistema orgânico de produção, consorciadas ou não com crotalária (Crotalaria juncea), e sem desbaste de ramos ou desbastadas a partir da terceira ramificação. A produtividade, em frutos de padrão comercial, alcançou média geral de $37 \mathrm{t} \mathrm{ha}^{-1}$, com o máximo próximo de $43 \mathrm{t} \mathrm{ha}^{-1}$. O híbrido Magali R produziu frutos mais pesados e longos do que a cultivar Magda Super. Entretanto, não houve diferença significativa entre as duas cultivares com relação à produtividade. Os frutos, tanto de Magali R quanto de Magda Super, ultrapassaram em média os $10 \mathrm{~cm}$ de comprimento mínimo para atingir a cotação "extra" de mercado. O número de frutos por planta aumentou nas parcelas não desbastadas, independentemente do consórcio. O desbaste de ramos reduziu o diâmetro basal médio, mas elevou o peso médio dos frutos, não influindo porém na produtividade. O híbrido Magali R apresentou apenas 15\% de plantas com sintomas de mosaico, ao final do ciclo produtivo, contra 38\% referentes à cv. Magda Super. O consórcio com a leguminosa resultou em ganho de produtividade e aumentou o comprimento dos frutos. Com a inclusão da crotalária, houve incremento do teor de nitrogênio nos frutos, bem como da quantidade desse elemento exportada na colheita.

\begin{abstract}
Performance of sweet pepper under organic cultivation, submitted to intercropping with crotalaria and branch pruning

Sweet pepper cultivars Magali R and Magda Super under organic management were compared, intercropped or not with Crotalaria juncea, and submitted or not to pruning starting from the third branch. Average yield of commercial fruits was $37 \mathrm{tha}^{-1}$ with maximum value of $43 \mathrm{tha}^{-1}$. The hybrid Magali R produced heavier and longer fruits than cv. Magda Super. However, no significant difference of productivity was found between cultivars. Fruits of both Magali R and Magda Super reached more than $10 \mathrm{~cm}$ of average length, the minimum required for highest market standard. The number of fruits increased in plants not submitted to pruning regardless of the process used. Branch pruning also reduced the average basal diameter of fruits and increased their average weight, without effect on productivity. $15 \%$ of the hybrid Magali R plants presented mosaic symptoms at the end of the vegetative cycle compared to $38 \%$ of Magda Super. Intercropping with crotalaria resulted in higher yields, increase of average fruit weight and nitrogen content of pepper fruits as well as in the amount of that element exported at harvest.
\end{abstract}

Keywords: Capsicum annuum, organic cultivation, green manuring.

Palavras-chave: Capsicum annuum, cultivo orgânico, adubação verde.

(Recebido para publicação em 30 de maio de 2006; aceito em 1 de agosto de 2007)

$\mathrm{O}$ cultivo de hortaliças requer alto nível tecnológico, pois em sua maioria, as espécies necessitam elevado aporte de insumos industriais (fertilizantes minerais de alta solubilidade, herbicidas e agrotóxicos) dentro de período de tempo relativamente curto. A produção intensiva de hortaliças requer freqüente preparo das áreas de cultivo, desestruturando o solo e expondo-o à insolação direta, o que resulta na redução do teor de matéria orgânica e da biota. A agricultura orgânica representa uma alternativa a esse modelo, sendo necessários, todavia, esforços para pesquisa e desenvolvimento de sistemas de cultivo sustentáveis e, sobretudo, viáveis para o agricultor familiar (Ribeiro et al., 1993).
Dentre as solanáceas cultivadas no estado do Rio de Janeiro, o pimentão (Capsicum annuum L.) assume lugar de destaque. Cultura caracterizada pela utilização massiva de agroquímicos, estima-se a produção estadual em torno de 26,4 t ano $^{-1}$, concentrada nas regiões Serrana e Centro-Sul Fluminense/Médio Paraíba, com ênfase para o município de Paty dos Alferes, de onde cerca de $8,5 \mathrm{t}$ foram comercializadas no Grande Rio em 2002 (Ceasa-RJ, 2002). Nestas regiões, o pimentão é cultivado em períodos de clima favorável, evitandose os meses frios, em que seu crescimento é prejudicado (Pádua, 1982). Por outro lado, nas regiões mais quentes do estado, como a Baixada Fluminense, o pimentão pode ser cultivado com sucesso durante o inverno, proporcionando maior lucratividade aos produtores, em função da oferta mais restrita e da forte demanda de mercado.

Dentre as práticas culturais direcionadas à conservação da fertilidade do solo destaca-se a adubação verde, usando primordialmente leguminosas como a Crotalaria juncea, eficazes quanto à simbiose com estirpes de rizóbio (Corak et al., 1991; Ehlers, 1999; Altieri, 2002). Existem variadas formas de adubação verde, sendo mais comum o sistema rotacional, em que resíduos do pré-cultivo de leguminosas, mediante os processos de decomposição e mineralização, liberam nutrientes para 
as culturas comerciais subseqüentes. Outra alternativa reside no cultivo consorciado ou adubação verde simultânea, que pode trazer vantagens adicionais como fornecimento de nitrogênio no momento de maior exigência da cultura de interesse econômico consorciada e controle mais eficaz de ervas espontâneas, com a conseqüente redução de mão-de-obra (Oliveira, 2001).

O desbaste de ramos pode acarretar benefícios sobre a produtividade e padrão comercial de frutos, pela influência exercida sobre a relação fonte-dreno (Berazi \& Favaro, 1988). No presente estudo procurou-se determinar os efeitos do consórcio com a Crotalaria juncea (crotalária) e do desbaste de ramos no desempenho produtivo de duas cultivares de pimentão, conduzidas sob manejo orgânico, nas condições climáticas de outono-inverno da Baixada Fluminense.

\section{MATERIAL E MÉTODOS}

O experimento foi conduzido no município de Seropédica, de abril a outubro de 2003. O solo é classificado como ARGISSOLO VERMELHO-AMARELO, cuja análise química $(0-20 \mathrm{~cm})$ revelou: $\mathrm{pH}$ em água=6,3; $\mathrm{Al}^{+3}=0,0 \mathrm{cmol} / \mathrm{dm}^{3}$; $\mathrm{Ca}^{+2}=3,9 \mathrm{cmol} / \mathrm{dm}^{3} ; \mathrm{Mg}^{+2}=1,4 \mathrm{cmol} / \mathrm{dm}^{3}$; $\mathrm{K}^{+}=165 \mathrm{mg} / \mathrm{kg} ; \mathrm{P}=200 \mathrm{mg} / \mathrm{kg}$.

Utilizou-se delineamento experimental de blocos casualizados, em esquema de parcelas subdivididas, com quatro repetições por tratamento. Os tratamentos foram representados por duas cultivares de pimentão, Magali R e Magda Super, consorciadas ou não com a crotalária (parcelas) e conduzidas sem desbaste de ramos ou desbastadas a partir da terceira ramificação (sub-parcelas). As parcelas comportaram 48 plantas, no espaçamento de 0,90 x 0,50 $\mathrm{m}$, dispostas em seis linhas de cultivo. A área útil constou das 12 plantas das duas linhas centrais de cada parcela, sendo seis delas desbastadas e as restantes não desbastadas, compondo as sub-parcelas.

As mudas de pimentão foram transplantadas 35 dias após a semeadura em bandejas de isopor (128 células) na casade-vegetação. Cada cova recebeu $1 \mathrm{~L}$ de esterco bovino curtido e $100 \mathrm{~g}$ de farinha de ossos. Além disso, foram procedidas três adubações mensais de cobertura com 100 g de "cama" de aviário e $50 \mathrm{~g}$ de farinha de ossos por planta. As análises da farinha de ossos revelaram: $\mathrm{N}=7,08 \mathrm{~g} \mathrm{~kg}^{-1}, \mathrm{Ca}^{+2}=445$ $\mathrm{g} \mathrm{kg}^{-1}, \mathrm{Mg}^{+2}=9,85 \mathrm{~g} \mathrm{~kg}^{-1}, \mathrm{P}=2,18 \mathrm{~g} \mathrm{~kg}^{-1}$, $\mathrm{K}^{+}=3,00 \mathrm{~g} \mathrm{~kg}^{-1}$; A análise da cama de aviário revelou: $\mathrm{N}=25,96 \mathrm{~g} \mathrm{~kg}^{-1}, \mathrm{Ca}^{+2}=65,25 \mathrm{~g}$ $\mathrm{kg}^{-1}, \mathrm{Mg}^{+2}=6,05 \mathrm{~g} \mathrm{~kg}^{-1}, \mathrm{P}=3,96 \mathrm{~g} \mathrm{~kg}^{-1}$, $\mathrm{K}^{+}=25,50 \mathrm{~g} \mathrm{~kg}^{-1}$; A análise do esterco bovino revelou: $\mathrm{N}=23,72 \mathrm{~g} \mathrm{~kg}^{-1}, \mathrm{Ca}^{+2}=16,56 \mathrm{~g}$ $\mathrm{kg}^{-1}, \mathrm{Mg}^{+2}=4,55 \mathrm{~g} \mathrm{~kg}^{-1}, \mathrm{P}=2,24 \mathrm{~g} \mathrm{~kg}^{-1}$, $\mathrm{K}^{+}=8,50 \mathrm{~g} \mathrm{~kg}^{-1}$. Calda sulfocálcica (1\%) foi aplicada semanalmente para controlar o ácaro branco (Polyphagotarsonemus latus) e o fungo Oidiopsis sp. Na fase inicial da cultura, empregou-se formulação comercial à base de Bacillus thuringiensis (0,5\%) para controle da lagarta rosca e de óleo de neem (0,5 \%) contra insetos mastigadores ("vaquinhas”) e sugadores (“pulgões”).

A crotalária foi semeada em cada entrelinha do pimentão, estabelecendo-se duas fileiras da leguminosa, espaçadas de 0,30 m entre si, na densidade de 30 sementes por metro linear de sulco. Após completa emergência, foi efetuado o raleamento para 10 plantas por metro linear. As duas fileiras centrais da crotalária foram cortadas com 27 dias, a contar do transplantio das mudas de pimentão (DAT); enquanto as restantes foram cortadas aos 45 DAT, sendo todo o material vegetal mantido em cobertura do solo junto às plantas de pimentão. Nessas ocasiões, foram estimadas as produções de biomassa aérea pela crotalária e retiradas amostras para determinação de umidade após acondicionamento em estufa de ventilação forçada a $65^{\circ} \mathrm{C}$, até o material atingir massa constante. Com base nos valores de matéria fresca e de umidade, calcularam-se as produções de matéria seca, nas respectivas datas de coleta. Determinaram-se, também, os teores de nitrogênio total ( $\mathrm{N}$-total) da biomassa aérea das plantas de crotalária, pelo método Kjeldahl (Alves et al., 1994).

Determinou-se a área foliar do pimentão, a incidência de plantas com sintomas de mosaico e a produtividade (frutos comercializáveis), além do comprimento, do diâmetro basal, do peso médio e do teor de nitrogênio total nos frutos. O comprimento e o diâmetro basal foram aferidos com auxílio de um paquímetro de mesa graduado em centímetros. Segundo a Portaria ${ }^{\circ}$ 855, de 27/11/1975, do Ministério da Agricultura, Pecuária e Abastecimento, frutos cônicos, com comprimento superior a 10 cm, enquadram-se no padrão "extra” para comercialização do pimentão in natura. A área foliar do pimentão foi estimada em amostras coletadas de planta inteira, com auxílio do Programa SIARCS 3.0 (Embrapa, 2003); enquanto a incidência de mosaico foi estabelecida mediante visualização dos sintomas, computando-se o percentual de plantas doentes por parcela, em data coincidente com cada uma de sete colheitas semanais consecutivas. Estimouse ainda a quantidade de $\mathrm{N}$-total exportada nos frutos colhidos, após secagem a $65^{\circ} \mathrm{C}$ até atingir massa constante.

\section{RESULTADOS E DISCUSSÃO}

A produtividade média alcançada no experimento foi expressiva, 37,1 t ha-1, com o melhor tratamento chegando a 43,3 t ha-1 . A analise de variância não apontou diferença significativa entre as duas cultivares testadas (Tabela 1).

O consórcio com crotalária teve influência positiva na produtividade do pimentão, considerando em conjunto as médias das cultivares (Tabela 1), possivelmente devido ao aporte suplementar de nutrientes que a adubação verde proporcionou. Após o corte das leguminosas, empregadas para cobertura do solo e adubação verde, ocorre imobilização temporária de nutrientes na biomassa, com progressiva liberação durante a decomposição da palhada (Espíndola et al.,1997). Além do nitrogênio liberado da biomassa roçada da leguminosa, dá-se uma transferência adicional desse nutriente oriundo da fixação biológica (Corak et al, 1991; Espíndola et al., 1997). Daí, pode-se depreender o efeito positivo sobre a produtividade do pimentão verificado no consórcio com a crotalária, cujo corte foi realizado antes do início da floração da solanácea. Parte do benefício pode ter sido proveniente do sombreamento inicial promovido pela crotalária, acelerando o “pegamento” das mudas transplantadas de pimentão e retendo umidade no solo. Sabe-se que o pimentão tolera certo nível de sombreamento, que pode melhorar seu desenvolvimento vegetativo (Schoch, 1972).

Com relação à área foliar (planta inteira), as cultivares diferiram entre si, 
Tabela 1. Produtividade, peso médio dos frutos e área foliar (planta inteira) de duas cultivares de pimentão submetidas ao manejo orgânico, em função do consórcio com Crotalaria juncea e do desbaste de ramos (Yield, average fruit weight and foliar área (of the complete plant) of two sweet pepper cvs. submitted to organic cultivation, as a result of consorciation with Crotalaria juncea and of branch pruning). Seropédica, UFRRJ, 2003.

\begin{tabular}{|c|c|c|c|c|c|}
\hline \multirow{3}{*}{ Cultivar } & \multicolumn{4}{|c|}{ Produtividade $\left(\mathrm{t} \mathrm{ha}^{-1}\right)$} & \multirow{3}{*}{$\begin{array}{l}\text { Efeito } \\
\text { cultivar }\end{array}$} \\
\hline & \multicolumn{2}{|c|}{ Consórcio } & \multicolumn{2}{|c|}{ Monocultivo } & \\
\hline & $\begin{array}{c}\text { com } \\
\text { desbaste }\end{array}$ & $\begin{array}{c}\text { sem } \\
\text { desbaste }\end{array}$ & $\begin{array}{c}\text { com } \\
\text { desbaste }\end{array}$ & $\begin{array}{c}\text { sem } \\
\text { desbaste }\end{array}$ & \\
\hline Magali R & $31,9 b^{1}$ & $41,2 a$ & $43,3 a$ & $37,4 b$ & $38,4 \mathrm{~A}$ \\
\hline Magda Super & $39,0 a$ & $36,7 a$ & $31,3 a$ & $35,6 a$ & $35,8 \mathrm{~A}$ \\
\hline Efeito Desbaste & $35,4 a$ & $38,9 a$ & $37,3 a$ & $36,5 a$ & \\
\hline Efeito Consórcio & \multicolumn{2}{|c|}{$37,5 a$} & \multicolumn{2}{|c|}{$36,9 b$} & \\
\hline \multirow[t]{2}{*}{$\mathrm{CV}(\%)$} & \multicolumn{4}{|c|}{7,60} & \\
\hline & \multicolumn{4}{|c|}{ Peso médio (g) } & \\
\hline Magali $\mathrm{R}$ & $79,84 a^{1}$ & $93,49 a$ & $107,47 a$ & $93,47 a$ & $93,57 \mathrm{~A}$ \\
\hline Magda Super & $106,53 a$ & $86,76 a$ & $80,69 a$ & $77,54 a$ & $87,88 \mathrm{~B}$ \\
\hline Efeito Desbaste & $93,18 a$ & $90,12 b$ & $94,08 a$ & $85,50 \mathrm{~b}$ & \\
\hline Efeito Consórcio & 91,6 & & & $9 a$ & \\
\hline \multirow[t]{2}{*}{$\mathrm{CV}(\%)$} & \multicolumn{4}{|c|}{10,63} & \\
\hline & \multicolumn{4}{|c|}{ Área foliar $\left(\mathrm{cm}^{2}\right)$} & \\
\hline Magali R & $4097,09 a^{1}$ & $3809,02 a$ & $3797,46 a$ & $4372,12 a$ & $4018,92 A$ \\
\hline Magda Super & $3636,42 a$ & $3541,30 a$ & $3823,16 a$ & $3766,20 a$ & $3691,77 \mathrm{~B}$ \\
\hline Efeito Desbaste & $2022,75 a$ & $3675,16 a$ & $3811,81 a$ & $4069,16 a$ & \\
\hline Efeito Consórcio & \multicolumn{2}{|c|}{$2848,95 a$} & \multicolumn{2}{|c|}{$3940,48 a$} & \\
\hline
\end{tabular}

${ }^{1}$ Médias seguidas da mesma letra minúscula nas linhas horizontais e maiúscula nas colunas não diferem entre si pelo teste de Tukey a $5 \%$ de probabilidade (means followed by the same small letters in the line and capital in the column did not differ from each other; Tukey, 5\%).

independentemente dos tratamentos (Tabela 1), fato que pode ser decorrente do vigor híbrido de Magali R. Esperava-se significância do efeito do desbaste de ramos em relação à área foliar, conforme registrado por Negreiros (1995). A não ocorrência desse efeito, no presente experimento, pode ser atribuída à alta freqüência de emissão de folhas pelas plantas de pimentão, superando os processos de senescência e abscisão, o que refletiria a adequabilidade do manejo orgânico empregado para a cultura.

O desbaste de ramos não resultou em aumento de produtividade, novamente considerando a média das duas cultivares (Tabela 1). Conforme esperado, o desbaste proporcionou aumento no peso médio dos frutos, confirmando resultados anteriormente reportados (Negreiros, 1995). Isto foi constatado em ambas modalidades de plantio (consórcio e monocultivo), reunindo-se as médias entre as duas cultivares de pimentão em cada tratamento (Tabela 1). O desbaste favoreceu o comprimento médio dos frutos e reduziu o diâmetro basal, independentemente do consórcio (Tabela 2).
O número reduzido de drenos, vegetativos e reprodutivos, nas plantas de pimentão desbastadas, foi o que provavelmente condicionou o tamanho maior dos frutos produzidos. É conhecido, por exemplo, que a relação fontedreno regula a disponibilidade de fotoassimilados e, conseqüentemente, influencia o desenvolvimento dos frutos de tomateiro (Yoshioka \& Takahashi, 1979; Oliveira, 1993).

Houve maior número de frutos por planta nas parcelas sem desbaste de ramos. Entretanto, somente para a cultivar Magda Super comprovou-se diferença significativa quanto à frutificação entre plantas desbastadas e não desbastadas, tanto no consórcio como no monocultivo (Tabela 2). Magda Super mostrou-se mais responsiva ao desbaste de ramos que Magali R, o que pode ser atribuído ao vigor híbrido da última cultivar, intensificando e acelerando a emissão de ramos produtivos. Por outro lado, as duas cultivares não diferiram quanto ao número de frutos comercializáveis no tratamento sem desbaste de ramos.
Esses resultados reforçam o resultado de Jaramillo et al. (1975), apontando relação direta entre número de frutos e número de ramos em plantas de pimentão. Também estão de acordo com estudos de Esiyok et al. (1994), que demonstraram que em plantas de pimentão desbastadas para apenas dois a três ramos havia redução significativa do número de frutos. Em tomateiro, analogamente, diversos autores (Machio \& Souza 1982; Lédo, 1998) constataram que o desbaste de ramos diminui significativamente a produção total de frutos, o que foi também registrado no Brasil por (Fontes et al., 1987; ChurataMasca \& Matuzita, 1992).

Os teores de nitrogênio determinados neste estudo (Tabela 3) foram mais elevados do que os encontrados por Miller et al. (1979) e por Negreiros (1995). Os números divulgados por Negreiros (1995), por sua vez, situaram-se abaixo daqueles obtidos por Furlani et al. (1978). Entretanto, todos esses valores também ultrapassaram o limite de 1,75\% considerado crítico em termos do teor de nitrogênio no fruto do pimentão (Miller et al., 1979). O efeito positivo do consórcio com a leguminosa, quanto ao teor de nitrogênio nos frutos, refletiria igualmente, o aporte suplementar de nitrogênio derivado da palhada roçada em decomposição oriundo tanto do solo quanto da fixação biológica de nitrogênio (FBN). Essa transferência da crotalária para o pimentão poderia representar um ganho ainda mais expressivo em condições de solo menos fértil ou com adubação orgânica em nível inferior à empregada no presente trabalho.

No monocultivo, a quantidade de nitrogênio exportado nos frutos foi menor do que no consórcio, para ambas as cultivares, em decorrência do menor teor de nitrogênio e da menor produtividade (Tabelas 1 e 3). Magali R e Magda Super também não diferiram entre si quanto a esse parâmetro (Tabela 3). Rocha et al. (2003) estimaram a exportação de nitrogênio pelos frutos de pimentão, trabalhando com os mesmos genótipos aqui utilizados, encontrando valores situados em torno de $20 \mathrm{~kg} \mathrm{ha}^{-1}$, comparáveis àqueles do presente estudo (Tabela 3).

Em adendo, a crotalária com 45 dias após semeada, produziu 7,2 t ha-1 de biomassa aérea fresca, correspondendo a 
1,7 t ha $^{-1}$ de matéria seca e a 74,36 kg de $\mathrm{N} \mathrm{ha}^{-1}$. Esses resultados são similares aos obtidos por Gouveia (1995), quando a crotalária foi semeada no final do verão: 6,8 e 1,5 t ha $^{-1}$, respectivamente, para produção de biomassa fresca e seca.

Alguns trabalhos conduzidos em condições climáticas semelhantes evidenciaram que a FBN na crotalária pode contribuir com mais de $90 \%$ do nitrogênio contido na parte aérea das plantas (Resende, 2000). Ribas et al. (2003), estudando a adubação verde na forma de consórcio envolvendo quiabeiro e $C$. juncea, em área contígua à do presente experimento, constataram que cerca de 50\% do nitrogênio contido na parte aérea da leguminosa foi derivado da FBN.

Com base nesta última estimativa, considerando que Ribas et al. (2003) empregaram manejo cultural equivalente, poder-se-ia hipotetizar que no caso presente, cerca de $34 \mathrm{~kg}$ de $\mathrm{N} \mathrm{ha}^{-1}$ acumulados na parte aérea da crotalária teriam sido derivados da FBN, representando assim, uma quantidade significativamente maior do que aquela exportada pelos frutos colhidos de pimentão (Tabela 3). Dessa forma, somente o processo de FBN associado à leguminosa, usada como adubo verde em consórcio com o pimentão, já poderia fornecer nitrogênio suficiente para um balanço positivo no sistema orgânico adotado, contribuindo inclusive para os ganhos na produção comercial e no comprimento dos frutos.

A cultivar Magda Super, embora apresentando ao final do ciclo, elevada incidência de plantas com sintomas de mosaico (Figura 1), produziu frutos de excelente padrão comercial no manejo adotado e em quantidade comparável à do híbrido Magali R, cujas sementes são muito mais caras no comércio nacional.

Este estudo apontou para a viabilidade do cultivo orgânico do pimentão, com semeadura de outono nas condições da Baixada Fluminense, visto que a média geral de produtividade obtida no ensaio enquadrou-se nos limites estimados para a cultura no Brasil, de 30 a 50 t ha ${ }^{-1}$, em sistema convencional (Filgueira, 2000).

A adubação verde, através do consórcio com $C$. juncea, acarretou benefícios à produtividade do pimentão, em sistema orgânico de cultivo, assim como o desbaste de ramos foi capaz de estimular o desenvolvimento dos frutos. Portanto, essas práticas poderiam ser
Tabela 2. Comprimento médio dos frutos, diâmetro basal médio e número de frutos por planta de duas cultivares de pimentão submetidas ao manejo orgânico, em função do consórcio com Crotalaria juncea e do desbaste de ramos (average fruit lenght, average basal diameter and number of fruits per plant of two sweet pepper cvs. submitted to organic cultivation, as a result of consorciation with Crotalaria juncea and of branch pruning). Seropédica, UFRRJ, 2003.

\begin{tabular}{|c|c|c|c|c|c|}
\hline \multirow{3}{*}{ Cultivar } & \multicolumn{4}{|c|}{ Comprimento médio dos frutos $(\mathrm{cm})$} & \multirow{3}{*}{$\begin{array}{l}\text { Efeito } \\
\text { cultivar }\end{array}$} \\
\hline & \multicolumn{2}{|c|}{ Consórcio } & \multicolumn{2}{|c|}{ Monocultivo } & \\
\hline & $\begin{array}{c}\text { com } \\
\text { desbaste }\end{array}$ & $\begin{array}{c}\text { sem } \\
\text { desbaste }\end{array}$ & $\begin{array}{c}\text { com } \\
\text { desbaste }\end{array}$ & $\begin{array}{c}\text { sem } \\
\text { desbaste }\end{array}$ & \\
\hline Magali R & $12,63 a^{1}$ & $12,35 a$ & $11,95 a$ & $11,31 \mathrm{~b}$ & $12,06 \mathrm{~A}$ \\
\hline Magda Super & $11,69 a$ & $11,26 a$ & $11,32 a$ & $10,97 a$ & $11,31 \mathrm{~B}$ \\
\hline Efeito Desbaste & $12,16 a$ & $11,80 \mathrm{~b}$ & $11,63 a$ & $11,14 b$ & \\
\hline Efeito Consórcio & \multicolumn{2}{|c|}{$12,49 a$} & \multicolumn{2}{|c|}{$11,95 b$} & \\
\hline \multirow[t]{2}{*}{ CV (\%) } & \multicolumn{4}{|c|}{2,97} & \\
\hline & \multicolumn{4}{|c|}{ Diâmetro basal médio dos frutos $(\mathrm{cm})$} & \\
\hline Magali R & $5,90 b^{1}$ & $6,15 a$ & $5,86 b$ & $6,26 a$ & $6,04 \mathrm{~A}$ \\
\hline Magda Super & $5,83 b$ & $6,08 a$ & $5,83 a$ & $6,02 a$ & $5,94 \mathrm{~A}$ \\
\hline Efeito Desbaste & $5,86 \mathrm{~b}$ & $6,11 \mathrm{a}$ & $5,84 \mathrm{~b}$ & $6,14 a$ & \\
\hline Efeito Consórcio & 5,9 & & & & \\
\hline \multirow[t]{2}{*}{$\mathrm{CV}(\%)$} & \multicolumn{4}{|c|}{2,27} & \\
\hline & \multicolumn{4}{|c|}{ Número total de frutos ${ }^{2}$} & \\
\hline Magali $\mathrm{R}$ & $108,25 a^{1}$ & $117,50 a$ & $109,75 a$ & $108,75 a$ & $108,25 \mathrm{~A}$ \\
\hline Magda Super & $99,75 b$ & $115,00 a$ & $104,25 b$ & $123,50 a$ & $99,75 \mathrm{~A}$ \\
\hline Efeito Desbaste & $104,00 b$ & $116,25 a$ & $107,00 \mathrm{~b}$ & $116,12 \mathrm{a}$ & \\
\hline Efeito Consórcio & \multicolumn{2}{|c|}{$108,25 a$} & \multicolumn{2}{|c|}{$109,75 a$} & \\
\hline
\end{tabular}

${ }^{1}$ Médias seguidas da mesma letra minúscula nas linhas horizontais e maiúscula nas colunas não diferem entre si pelo teste de Tukey a 5\% de probabilidade; ${ }^{2}$ os valores correspondem a seis plantas por tratamento contidas na área útil de cada parcela experimental ( ${ }^{1}$ means followed by the same small letters in the line and capital in the column did not differ from each other; Tukey, 5\%; ${ }^{2}$ the values correspond to six plants in each treatment).

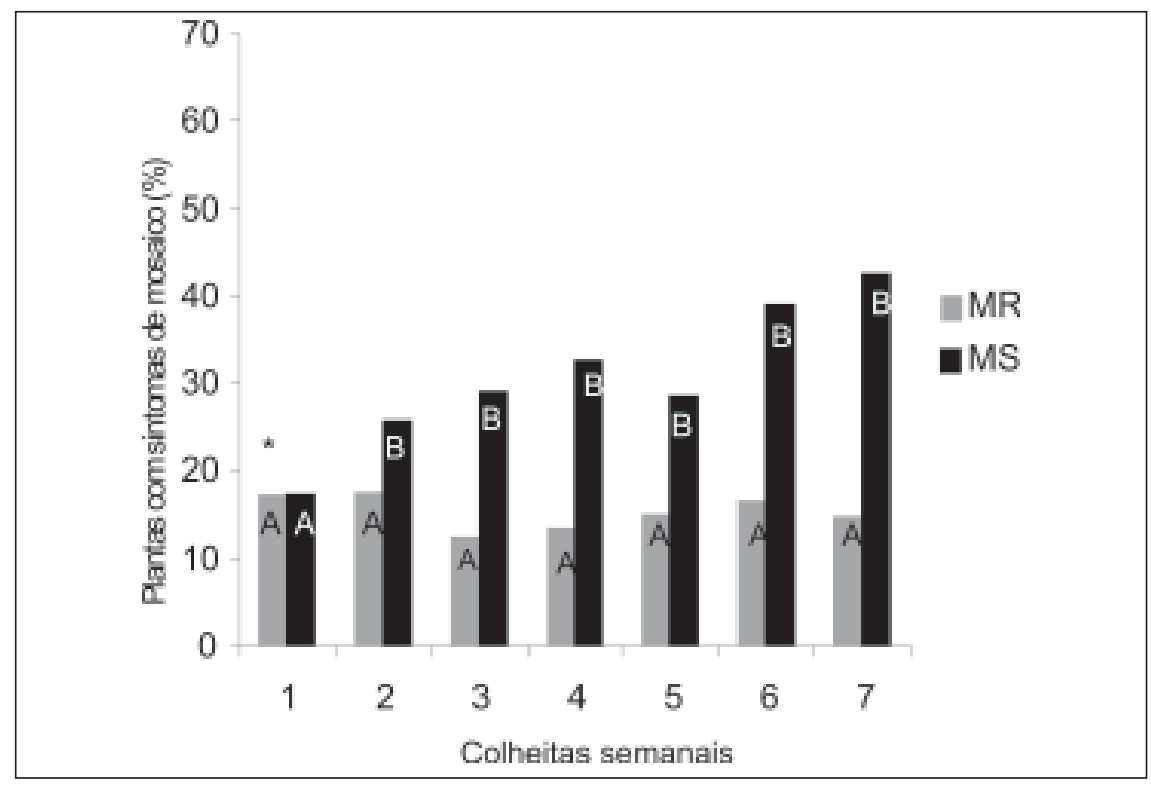

Figura 1. Incidência de sintomas de mosaico em duas cultivares de pimentão, Magali R (MR) e Magda Super (MS), submetidas ao manejo orgânico nas condições edafoclimáticas da Baixada Fluminense (mosaic symptoms in two sweet pepper cvs., Magali R (MR) and Magda Super (MS), submitted to organic cultivation under the climatic conditions of the Baixada Fluminense). Seropédica- RJ, 2003.

*Médias seguidas da mesma letra, em cada colheita, não diferem entre si pelo teste de Tukey a $5 \%$ de probabilidade ( ${ }^{*}$ means followed by the same small letters in the line and capital in the column did not differ from each other; Tukey, 5\%). 
Tabela 3. Teor de nitrogênio nos frutos e quantidade exportada na colheita de duas cultivares de pimentão submetidas ao manejo orgânico, em função do consórcio com Crotalaria juncea e do desbaste de ramos (Nitrogen content in the fruits and exported quantity of two sweet pepper cvs. submitted to organic cultivation, as a result of consorciation with Crotalaria juncea and of branch pruning) Seropédica, UFRRJ, 2003.

\begin{tabular}{|c|c|c|c|c|c|}
\hline \multirow{3}{*}{ Cultivar } & \multicolumn{4}{|c|}{ Teor de $\mathrm{N}$ nos frutos $\left(\mathrm{g} \mathrm{kg}^{-1}\right)$} & \multirow{3}{*}{$\begin{array}{l}\text { Efeito } \\
\text { cultivar }\end{array}$} \\
\hline & \multicolumn{2}{|c|}{ Consórcio } & \multicolumn{2}{|c|}{ Monocultivo } & \\
\hline & $\begin{array}{c}\text { com } \\
\text { desbaste }\end{array}$ & $\begin{array}{c}\text { sem } \\
\text { desbaste }\end{array}$ & $\begin{array}{c}\text { com } \\
\text { desbaste }\end{array}$ & $\begin{array}{c}\text { sem } \\
\text { desbaste }\end{array}$ & \\
\hline Magali R & $38,8 a^{1}$ & $35,1 b$ & $32,2 a$ & $29,2 a$ & $33,8 \mathrm{~A}$ \\
\hline Magda Super & $35,6 a$ & $34,4 a$ & $31,8 a$ & $27,4 a$ & $32,3 \mathrm{~A}$ \\
\hline Efeito Desbaste & $37,2 a$ & $34,7 a$ & $32,0 a$ & $28,3 a$ & \\
\hline Efeito Consórcio & \multicolumn{2}{|c|}{$35,9 a$} & \multicolumn{2}{|c|}{$30,1 b$} & \\
\hline CV (\%) & \multicolumn{4}{|c|}{10,11} & \\
\hline \multicolumn{6}{|c|}{ Desdobramento da interação cultivar $\mathrm{x}$ desbaste no teor de $\mathrm{N}$ dos frutos } \\
\hline Cultivar & \multicolumn{2}{|c|}{ Com desbaste } & \multicolumn{3}{|c|}{ Sem desbaste } \\
\hline Magali R & \multicolumn{2}{|c|}{$19,18 \mathrm{Aa}^{1}$} & \multicolumn{3}{|c|}{$21,64 \mathrm{Aa}$} \\
\hline Magda Super & \multicolumn{2}{|c|}{$16,92 \mathrm{Aa}$} & \multicolumn{3}{|c|}{$15,21 \mathrm{Ab}$} \\
\hline $\mathrm{CV}(\%)$ & & & & & \\
\hline \multicolumn{6}{|c|}{ Quantidade de $\mathbf{N}$ exportada pelos frutos de pimentão colhidos (kg ha-1) } \\
\hline Magali R & $23,48 a^{1}$ & $26,28 a$ & $14,86 a$ & $16,99 a$ & $20,40 \mathrm{~A}$ \\
\hline Magda Super & $22,25 a$ & $19,25 a$ & $10,99 a$ & $11,16 a$ & $17,09 \mathrm{~B}$ \\
\hline Efeito Desbaste & $22,86 a$ & $22,76 a$ & $12,92 a$ & $14,07 a$ & \\
\hline Efeito Consórcio & \multicolumn{2}{|c|}{$108,25 a$} & \multicolumn{2}{|c|}{$13,49 b$} & \\
\hline $\mathrm{CV}(\%)$ & & & & & \\
\hline
\end{tabular}

${ }^{1}$ Médias seguidas da mesma letra minúscula nas linhas horizontais e maiúscula nas colunas não diferem entre si pelo teste de Tukey a 5\% de probabilidade ( ${ }^{1}$ means followed by the same small letters in the line and capital in the column did not differ from each other; Tukey, 5\%).

recomendadas aos agricultores orgânicos da Baixada Fluminense e de outras localidades da Região Metropolitana do estado do Rio de Janeiro com características edafoclimáticas similares.

\section{REFERÊNCIAS}

ALTIERI M. 2002. Agroecologia: bases científicas para uma agricultura sustentável. Guaíba: Agropecuária. 592p.

ALVES BJR; SANTOS JCF; URQUIAGA S; BODDEY, RM. 1994. Métodos de determinação de nitrogênio em tecidos de planta. In: HUNGRIA M; ARAUJO RS (eds.) Manual de métodos empregados em estudo de microbiologia agrícola. Londrina: Embrapa Arroz e Feijão. p. 449-4467. (Embrapa Arroz e Feijão. Documentos, 46).

BERAZI NT; FAVARO JL. 1988. Manejo de la poda del pimiento cultivado en invernadero. Horticultura Argentina 7: 28-31.

CEASA-RJ. Oferta de pimentão no estado do Rio de Janeiro, 2002. Disponível em http: www.ceasarj.gov.br. Acessado em 20 de fevereiro de 2003.

CHURATA-MASCA MGC; MATUZITA K. 1992. Efeito da densidade, poda e desbaste de frutos na produção comercial de tomate. In: CONGRESSO DA SOCIEDADE DE OLERICULTURA DO BRASIL, 32. Anais.... Aracajú: SOB. p. 32-38.

CORAK SJ; FRYE WW; SMITH MS. 1991. Le- gume mulch and nitrogen fertilizer effects on soil water and corn production. Soil Science Society of America Journal 55: 1305-1400.

EHLERS E. 1999. Agricultura sustentável. Guaíba: Agropecuária. 157 p.

EMBRAPA. Centro Nacional de Pesquisa e Desenvolvimento de Instrumentação Agropecuária. SIARCS - Sistema Integrado para Análise de Raízes e Cobertura do Solo. 2003.

ESIYOK D; ÖZZAMBAK E; ESER B. 1994. The effects of stem pruning on the yield and earliness of greenhouse peppers (Capsicum annuum L. grossum cv. Kandil and 11B-14). Acta Horticulturae 366: 293-300.

ESPÍNDOLA JAA; GUERRA JGM; ALMEIDA DL. 1997. Adubação verde: estratégia para uma agricultura sustentável. Seropédica: Embrapa Agrobiologia. 20 p. (EmbrapaCNPAB. Documentos, 42).

FILGUEIRA FAR. 2000. Novo manual de olericultura. Viçosa: UFV. 402 p.

FONTES PCR; NAZAR RA; CAMPOS JP. 1987. Produção e rentabilidade da cultura do tomateiro afetadas pela fertilização e pelo sistema de condução. Revista Ceres 34: 355-365.

FURLANI AMC; FURLANI OC; HIROCE JR; GALLO JR. 1978. Composição mineral de diversas hortaliças. Bragantia 37: 33-44.

GOUVEIA RF. 1995. Possibilidades de adubação verde no município de Paty do Alferes/RJ. Seropédica: UFRRJ. 129p. (Tese mestrado).

LÉDO FJS. 1998. Sistemas de condução da plan- ta, visando ao consumo "in natura”, em seis cultivares de tomate (Lycopersicon esculentum Mill.) de crescimento determinado. Viçosa: UFV. 58p. (Tese mestrado).

JARAMILLO LDO; AGUIRRE RDV; CABRERA FAV. 1975. Respuesta del tomate (Licopersicon esculentum Mill.) a diferentes sistemas de poda. Acta Agronomia 25: 86-110.

MACHIO LMA; SOUZA GF. 1982. Adubação básica, nitrogênio em cobertura, espaçamento e desbrota na produção de tomateiro. Pesquisa Agropecuária Brasileira 17: 1309-1315.

MILLER CH; McCOLLUM RE; CLAIMON S. 1979. Relationships between growth of bell peppers and nutrient accumulation during ontogeny in field environments. Journal of the American Society for Horticultural Science 104: 852-857.

NEGREIROS MZ. 1995. Crescimento, partição de matéria seca, produção e acúmulo de macronutrientes de plantas de pimentão(Capsicum annuum L.) em cultivo podado e com cobertura morta. Viçosa: UFV.187p (Tese doutorado).

OLIVEIRA VR. 1993. Número de ramos por plantas, poda apical e época de plantio influenciando a produção e qualidade dos frutos de tomateiro (Lycopersicon esculentum Mill.) cv. Kadá. Viçosa: UFV. 114p (Tese mestrado).

OLIVEIRA FL. 2001. Manejo orgânico da cultura do repolho (Brassica oleracea var. capitata): adubação orgânica, adubação verde e consorciação. Seropédica: UFRRJ. 87p. (Tese mestrado).

PÁDUA JG. 1982. Aspectos climáticos na cultura do pimentão (Capsicum annuum). In: MILLER JJVE; CASALI VWD (eds.) SEMINÁRIO DE OLERICULTURA. Viçosa: UFV. p.387-413.

RESENDE AS. 2000. Fixação biológica de nitrogênio (FBN) como suporte da fertilidade nitrogenada dos solos e da produtividade da cultura de cana-de-açúcar: uso de adubos verdes. Seropédica: UFRRJ. 143p (Tese mestrado).

RIBAS RGT; JUNQUEIRA RM; OLIVEIRA FL; GUERRA JGM; ALMEIDA DL; RIBEIRO RLD. 2003. Desempenho do quiabeiro (Albelmoschus esculentus) consorciado com Crotalaria juncea sob manejo orgânico. Revista Agronomia 37: 80-84.

RIBEIRO MFS; MERTEN GH; SKORA NETO F. 1993. Plantio na palha na pequena propriedade. In: EMBRAPA. CNPT/FECOTRIGO/ FUNDAÇÃO ABC. (eds.). Plantio direto no Brasil. Passo Fundo: Aldeia Norte. p. 37-60.

ROCHA CM; GEDDA EA; MANERA CT; SILVA GAD; CARMO FGM; POLIDORO JC; FERNANDES ACM. 2003. Produtividade e exportação de $\mathrm{N}$ e de $\mathrm{K}$ na cultura do pimentão (Capsicum annuum L.) influenciadas pela aplicação foliar de biofertilizante e bactericidas. Revista Agronomia 37: 42-45.

SCHOCH PG. 1972. Effects of shading on structural characteristics of the leaf and yield of fruit in Capsicum annuum L. Journal of the American Society for Horticultural Science 97: 446-464.

YOSHIOKA H; TAKAHASHI K. 1979. Studies on translocation and accumulation of photosynthates in fruit vegetables. II. The translocation and distribution of ${ }^{14} \mathrm{C}$-photosynthates in tomato plants during reproductive development and effects of topping and shading. Bulletin of Vegetable \& Ornamental Crops Statistics 6: 71-84. 